\section{FAMILY PLANNING VILLAGE: FROM GAPURA TO FAMILY QUALITY OF LIFE}

\section{KAMPUNGKELUARGA BERENCANA: \\ DARI GAPURA KE KUALITAS HIDUP KELUARGA}

Jurnal Pendidikan Luar Sekolah

http://kolokium.ppj.unp.ac.id/ Jurusan Pendidikan Luar Sekolah

Fakultas Ilmu Pendidikan

Universitas Negeri Padang

Sumatera Barat, Indonesia

Volume 8, Nomor 2, 2020

DOI: 10.24036/kolokium-pls.v8i2.433

Received 14 August 2020

Approved 27 October 2020

Published 30 October 2020

\author{
Moh. Tohirin Hasan', Iswandi \\ ${ }^{1}$ Pusdiklat Kependudukan dan KB, BKKBN \\ ${ }^{2}$ Universitas Bhakti Kencana, Banten \\ ${ }_{3}^{3}$ Email: tohirinhasan@yahoo.com
}

\begin{abstract}
Since its launch in 2016, the Family Planning Village (Kampung KB) has experienced interesting dynamics in the field. The number of KB Kampung is increasing every year. One of the goals of the $\mathrm{KB}$ Village is to improve the family quality of life. Quality of life consist of the physical, emotional, social, intellectual, spiritual, and environmental dimensions. This literature review research explores two questions: (1) how is the implementation of KB Kampung in the field; (2) What are the implications of Kampung KB for the quality of family life. By using Crossref and Google Scholar, 97 writings on the theme of Kampung KB were obtained. After the exclusion, there were 33 papers that were relevant to the purpose of this study, only 23 papers were obtained which were used as exploration material. The results of the analysis show several things. First, Kampung KB has been implemented with various obstacles and opportunities. Some that are often encountered are: lack of understanding of the managers, lack of budget support, and low continuity of activities. Second, although the community has felt the benefits, the programs and activities have not had too many implications for the family quality of life.
\end{abstract}

Keywords: Family Planning Village, Implementation, Family Quality of Life

\begin{abstract}
ABSTRAK
Sejak digulirkan pada 2016 Kampung Keluarga Berencana (Kampung KB) mengalami dinamika yang menarik di lapangan. Secara kuantitatif, jumlah Kampung KB semakin bertambah tiap tahun. Salah satu tujuan dibentuk Kampung KB adalah meningkatkan kualitas hidup keluarga. Kualitas hidup diartikan sebagai persepsi individu tentang posisinya dalam kehidupan yang diukur secara keseluruhan, meliputi dimensi fisik, emosional, sosial, intelektual, spiritual, dan lingkungan. Penelitian litiratur review ini mengeksplorasi dua pertanyaan: (1) bagaimana implementasi Kampung KB di lapangan; (2) Bagaimana implikasi Kampung KB bagi kualitas hidup keluarga. Dengan menggunakan Crossref dan Google Scholar didapat 97 tulisan yang bertema Kampung KB. Setelah dilakukan eksklusi terdapat 33 tulisan yang relevan dengan tujuan penelitian ini. Sepuluh diantaranya dikeluarkan karena tidak tersedia naskah lengkap, sehingga didapat 23 naskah yang dijadikan bahan eksplorasi. Hasil analisis
\end{abstract}


menunjukkan beberapa hal. Pertama, Kampung KB sudah diimplementasikan dengan hambatan dan peluang yang beragam di lapangan. Beberapa yang sering ditemuai adalah: kurangnya pemahaman pengelola, minimnya dukungan anggaran, serta rendahnya kontinuitas kegiatan di Kampung KB. Kedua, meskipun masyarakat sudah merasakan manfaat, tapi program dan kegiatan belum terlalu banyak berimplikasi pada kualitas hidup keluarga.

Kata Kunci: Kampung KB, Implementasi, Kualitas Hidup Keluarga

\section{PENDAHULUAN}

Pembangunan Kependudukan dan Keluarga Berencana menghadapi tantangan yang semakin kompleks seiring dengan perubahan lingkungan strategis. Perubahan-perubahan tersebut antara lain: mendesaknya penguatan advokasi dan KIE, peningkatan akses dan kualitas pelayanan KB yang merata, peningkatan pemahaman dan kesadaran remaja mengenai kesehatan reproduksi serta penyiapan kehidupan berkeluarga, pembangunan keluarga melalui pembinaan ketahanan dan kesejahteraan keluarga, penguatan landasan hukum dalam rangka optimalisasi pelaksanaan pembangunan bidang Kependudukan dan KB, serta penguatan data dan informasi Kependudukan, KB dan KS (BKKBN, 2015).

Dalam situasi dan kondisi demikian, diperlukan integrasi dan sinergi Program Kependudukan dan KB dengan program pembangunan lain dengan menempatkan penduduk sebagai subyek. Penduduk perlu diberdayakan dan ditingkatkan kapasitasnya secara berkesinambungan. Dengan cara demikian, terbuka lebar kesempatan bagi penduduk untuk turut serta dalam dalam pembangunan. Hal ini sesuai dengan agenda prioritas pembangunan yaitu, meningkatkan kualitas hidup manusia Indonesia melalui pembangunan kependudukan dan $\mathrm{KB}$.

Upaya pengendalian pertumbuhan penduduk dilakukan melalui Program Kependudukan, Keluarga Berencana dan Pembangunan Keluarga dalam rangka mewujudkan norma keluarga kecil, bahagia, dan sejahtera. Melalui program tersebut diharapkan dapat memberikan kontribusi terhadap perubahan kuantitas penduduk yang ditandai dengan perubahan jumlah, struktur, komposisi dan persebaran penduduk yang seimbang.

Keberhasilan program KKBPK akan menyebabkan pergeseran distribusi umur penduduk dan penurunan rasio ketergantungan penduduk muda (youth dependency ratio). Akan tercipta keadaan ideal yang menghasilkan potensi terjadinya bonus demografi. Artinya, jumlah penduduk usia kerja hampir dua kali dibandingkan dengan jumlah penduduk di bawah 15 tahun. Rasio ketergantungan penduduk Indonesia menurun dari 54/100 pada tahun 2000 menjadi 51/100 pada tahun 2011 dan turun menjadi 50/100 tahun 2012. Kondisi ini akan menurun terus mencapai angka terendah pada tahun 2020 sampai 2030, angkanya berkisar 44 per 100 (BKKBN, 2015).

Bonus demografi, jika dimanfaatkan akan menghasilkan jendela peluang atau window of opportunity untuk memicu pertumbuhan ekonomi termasuk peningkatan ketahanan pangan dalam rangka kemandirian bangsa. Pada saat bersamaan akan menghasilkan kualitas penduduk usia produktif yang tinggi sehingga menjadi modal pembangunan bangsa. 
Oleh karena itu, diperlukan langkah-langkah strategis dalam pemanfaatan peluang bonus demografi perlu disiapkan. Langkah-langkah strategis tersebut bermuara pada penurunan laju pertumbuhan penduduk (LPP), angka kelahiran total (TFR), peningkatan pemakaian kontrasepsi (CPR), penurunan kebutuhan ber-KB yang tidak terpenuhi (unmet need), penurunan angka kelahiran pada remaja usia 15-19 tahun (ASFR 15-19 tahun), serta penurunan kehamilan yang tidak diinginkan dari wanita usia subur (WUS) (15-49 tahun).

Dalam mewujudkan langkah-langkah di atas, BKKBN menginisiasi Program Pengembangan Kampung KB. Kampung KB adalah satuan wilayah setingkat RW, dusun atau setara, yang memiliki kriteria tertentu di mana terdapat keterpaduan program KKBPK dan pembangunan sektor terkait yang dilaksanakan secara sistemik dan sistematis. Tujuan dibentuknya Kampung KB adalah untuk meningkatkan kualitas hidup masyarakat di tingkat kampung atau yang setara melalui program kependudukan, keluarga berencana dan pembangunan keluarga serta pembangunan sektor terkait dalam rangka mewujudkan keluarga kecil berkualitas.

Mengacu pada definisi World Health Organization, kualitas hidup adalah persepsi individu mengenai posisi seseorang dalam kehidupan dilihat dari konteks budaya dan sistem nilai di mana mereka tinggal serta hubungannya dengan tujuan, harapan, standar, dan hal-hal lain yang menjadi perhatian individu tersebut. Pengertian ini menekankan bahwa kualitas hidup adalah persepsi seseorang mengenai posisi kehidupannya yang didasarkan pada sistem budaya di mana ia hidup dan juga dipengaruhi oleh tujuan, harapan dan standar dari masingmasing individu.

Sampai saat ini, peningkatan kualitas hidup merupakan topik yang menarik untuk dikaji. Seetidaknya, dalam dua dekade terakhir masyarakat dunia sangat sibuk membincangkan isu ini. Dalam dokumen Sustainable Development Goal's, secara jelas dinyatakan no poverty yang berarti dunia sepakat untuk mengakhiri kemiskinan dan meningkatkan kesejahteraan penduduk. Ini berarti bahwa negara-negara di dunia, tak terkecuali Indonesia, bersepakat untuk meningkatkan kualitas hidup manusia, melalui peningkatan kesejahteraan hidup, pendidikan, kesehatan dan lain sebagainya. Tulisan berikut mengeksplorasi implementasi Kampung KB dan implikasinya bagi kualitas hidup masyarakat. Kajian ini ingin menjawab dua pertanyaan: (1) bagaimana implementasi Kampung KB di lapangan; (2) Bagaimana implikasi Program Kampung KB bagi kualitas hidup masyarakat setempat?

\section{METODE}

Desain penelitian ini adalah literature review, yaitu mengumpulkan data atau sumber yang berhubungan dengan topik Kampung KB yang didapat dari berbagai (Hakim, 1987) (Nasir, 1985) (Zed, 2014). Penelusuran artikel publikasi pada Crossref dan Google Scholar menggunakan kata kunci yang dipilih yakni: kampung KB, implementasi, efektifitas, dan kualiatas hidup. Artikel atau jurnal yang sesuai dengan kriteria inklusi dan eksklusi diambil untuk selanjutnya dianalisis. Literature Review ini menggunakan terbitan 2016-2020 yang dapat diakses fulltext dalam format pdf. Kriteria jurnal yang direview adalah artikel jurnal penelitian berbahasa Indonesia dan Inggris. Jurnal yang sesuai dengan kriteria inklusi dan terdapat tema Kampung KB kemudian dilakukan review. 


\section{PEMBAHASAN}

\section{Implementasi Kampung KB: Dari Gapura ke Kualitas Hidup Keluarga}

Meski dengan segala keterbatasan, sebagian besar program Kampung KB sudah berjalan di masing-masing daerah. Keberhasilan implementasi kampung $\mathrm{KB}$ sangat bergantung pada banyak faktor (Aji, Maulana Satria, \& Yudianto, 2020) (Bachtiyar, Nosa Arighi, \& Wibawani, 2018) (Hidayah, Seventina Nurul, \& Latifah, 2018) (HM, Rahman, \& Indrawadi, 2019) (Nurjannah, Siti Nunung, \& Susanti, 2018). Faktor yang tidak tunggal ini mengakibatkan pelaksanaan Kampung KB antar satu daerah dan daerah lain tidak sama. Semua bergulir dinamis sesuai dengan peluang dan hambatan yang ada di lapangan. Situasi ini menuntut pengelola Kampung KB untuk secara kreatif dan inovatif melipatgandakan potensi, kekuatan dan kelebihan lingkungannya untuk mengakselarasi pelaksanan Kampung $\mathrm{KB}$.

Sekaitan dengan ini, (Aisyah, 2020) dalam studi kualitatif yang dilakukan menemukan dua hal yang menarik. Pertama, rendahnya pendidikan merupakan pemicu kekurangpahaman masyarakat terhadap tujuan Kampung KB. Kedua, implementasi Kampung KB meski dengan segala keterbatasan telah membawa dampak positif bagi kesejahteraan masyarakat dari sisi ekonomi dan pendidikan.

Namun demikian, sebagian masyarakat yang kurang memahami sering mengabaikan program ini. Temuan (Restiyani, Ni Luh Novi dan Yasa, 2019) menunjukkan bahwa pendidikan dan peran petugas KB berpengaruh positif dan signifikan terhadap efektivitas program Kampung KB. Hal ini menunjukan bahwa semakin tinggi pendidikan dan semakin aktif petugas KB, maka pelaksanaan program Kampung KB akan semakin berjalan efektif.

(Arinta, 2018) menggunakan lima indikator untuk mengukur efektifitas program Kampung KB, yaitu: pemahaman program, ketepatan sasaran, ketepatan waktu, pencapaian tujuan, dan perubahan nyata. Hasil kajiannya menunjukkan bahwa, meski tidak utuh dan menyeluruh masyarakat telah memahami program Kampung KB. Masyarakat memahami Kampung KB sebagai program yang bertujuan untuk mengendalikan laju pertumbuhan penduduk, mengentaskan kemiskinan, juga untuk membangun keluarga. Mereka juga mengetahui manfaat sosial, ekonomi dan emosional untuk diri dan keluarga. Selebihnya, meskipun pencapaian tujuan Kampung KB belum efektif, tapi dari indikator ketepatan sasaran, ketepatan waktu, dan perubahan nyata sudah berjalan efektif.

Serupa dengan temuan di atas, kajian (Nafisah, 2018) tentang efektifitas program Kampung KB dalam membentuk keluarga sejahtera menarik untuk disimak. Dalam penelitiannya didapat dua kesimpulan besar. Pertama, selain selain program unggulan berupa $\mathrm{BKB}, \mathrm{BKR}, \mathrm{BKL}$, dan UPPKS, setiap Kampung KB mempunyai program tambahan. Program tambahan ini didasarkan pada permasalahan masing-masing kampung. Kedua, faktor yang melatarbelakangi dibentuknya Kampung KB adalah rendahnya angka kepesertaan $\mathrm{KB}$, banyaknya remaja yang melakukan pernikahan dini, wilayah yang kumuh, daerah aliran sungai, kawasan miskin perkotaan, serta padat penduduk.

Selanjutnya, (Handayani, dkk 2020) secara purposif melakukan evaluasi Kampung KB di Kota Magelang, Kabupaten Sukoharjo, dan Kabupaten Temanggung. Hasilnya, pertama, berkaitan dengan input yakni pembentukan wilayah kampung KB sudah sesuai pedoman, partisipasi masyarakat cukup baik, namun dukungan sarana dan prasarana masih sangat minim. Kedua, berkaitan dengan proses yakni data, pembinaan dan penggerakan 
belum terjadwal secara rutin. Ketiga, berkaitan dengan output yakni bentuk kegiatan di kampung KB sudah cukup lengkap antara lain: Tri Bina (Bina Keluarga Balita, Bina Keluarga Remaja, Bina Keluarga Lansia), Usaha Peningkatan Pendapatan Keluarga Sejahtera (UPPKS), Pusat Informasi dan Konseling Remaja (PIK/R), bimbingan belajar dan perpustakaan pintar, serta kegiatan lintas sektor meliputi drainase, jambanisasi, pembibitan jagung, bank sampah, pelatihan home industry, pelatihan ternak bebek, dan perbaikan infrastruktur.

Benang merah dari temuan-temuan di atas adalah bahwa, selain pemahaman masyarakat dan pengelola Kampung KB, keberagaman potensi lingkungan, kerjasama lintas bidang juga tak bisa diabaikan. Hal ini sekaligus menegaskan bahwa keberhasilan pelaksnaan Kampung KB memerlukan sinergi dan integrasi lintas sektor. Dalam konteks ini komunikasi dan koordinasi lintas sektor dapat menjadi pintu pembuka untuk mewujudkannya. Koordinasi memiliki pengaruh besar terhadap efektivitas pelayanan di Kampung KB (Ningrum, 2020). Pelayanan akan berjalan baik jika terjalin koordinasi yang baik antar petugas pelayanan dan pihak-pihak terkait. Dengan koordinasi yang baik maka akan menghasilkan kerjasama tim yang kokoh, tanggungjawab terhadap tugas, komitmen dalam melaksanakan pelayanan, serta mampu memberikan pelayanan yang sesuai dengan target dan sasaran dari kegiatan-kegiatan di Kampung KB.

Hingga saat ini, jumlah Kampung KB setidaknya sudah melampaui angka 13.679 yang tersebar di seluruh Indonesia (BKKBN, 2019). Jika ditelusuri lebih jauh, meskipun secara kuantitatif angkanya sudah mencapai ribuan, implementasi kebijakan tentang program Kampung KB menuju keluarga sejahtera belum menunjukkan hasil yang memuaskan. Ini sejalan dengan kajian (BKKBN, 2018) yang menemukan bahwa setelah pencanangan Kampung KB, pelaksanaan di lapangan belum seperti yang diharapkan. Dari sekian banyak lokasi kampung $\mathrm{KB}$ yang telah dicanangkan terdapat variasi yang sangat besar dalam pelaksanaan di lapangan.

Situasi di atas terjadi karena faktor content of policy (isi kebijakan) dan context of implementation (konteks implementasi) yang belum maksimal (Muliawaty, 2019). Dalam penelitiannya, ditemukan strategi yang efektif untuk dapat mengoptimalkan implementasi kebijakan Program Kampung KB menuju terwujudnya keluarga sejahtera, yakni strategi deversifikasi. Pertama, mengoptimalkan kemampuan dan keterampilan melelui mekanisme program dengan utuh untuk mengoptimalkan pembinaan institusi masyarakat secara berkesinambungan. Kedua, Program Kampung KB sebagai program unggulan pemerintah, harus ditunjang dengan sarana pendukung yang optimal. Ketiga, mengoptimalkan kegiatan bina keluarga didukung oleh peningkatan respon dari pelaksana program dalam mewujudkan keluarga sejahtera. Keempat, menumbuhkan partisipasi masyarakat melalui metode musyawarah partisipatif dalam menentukan kegiatan atau kepentingan masyarakat untuk dapat menumbuhkan partisipasi dalam meningkatkan derajat kesehatan lingkungan. Lebih lanjut mereka menambahkan pentingnya tiga faktor lain yang harus diperhatikan untuk mewujudkan keberhasilan implementasi Kampung KB, yaitu: sinergitas kelembagaan (institutional synergies), kekuatan agama dan budaya (religious and cultural forces), serta pemberdayaan masyarakat (community empowerment).

Dari berbagai temuan penelitian, pemahaman tentang Kampung KB, koordinasi, dan kolaborasi merupakan faktor penting dan selalu muncul (Normajatun, Normajatun, Malawat, Sitna Hajar, \& Fibriyanita, 2019). Temuan-temuan ini memang sungguh logis, sebab hanya dengan pemahaman yang benar seseorang akan terbuka pikiran yang pada gilirannya akan berbuah suatu tindakan. Dengan demikian, partisipasi masyarakat dalam program Kampung 
KB dapat terwujud jika ada pemahaman yang mengawalinya. Sebab itu diperlukan sosialisasi program yang mudah dipahami dan dilakukan secara masif dengan memahami kultur masyarakat setempat.

Sekaitan dengan pentingnya pemahaman Kampung KB, (Nugroho Muhammad, dkk 2018) mengidentifikasi tahapan-tahapan penerimaan masyarakat terhadap program Kampung KB sebagai sebuah inovasi. Tahapan-tahapan tersebut adalah tahap pengetahuan, tahap ajakan, tahap pengambilan keputusan, tahap penerapan, serta tahap konfirmasi. Upaya gigih yang dilakukan oleh PLKB dan Pokja Kampung KB untuk mengajak dan menanamkan pengetahuan pada akhirnya membuat masyarakat memutuskan untuk mengadopsi inovasi ini. Selain itu adanya sebuah sistem sosial modern di tengah-tengah masyarakat Pucangsawit, menciptakan pola pemikiran terbuka dengan hal-hal baru, termasuk program Kampung KB ini.

Untuk memberi pemahaman dan memperkecil kemungkinan penolakan dari masyarakat diperlukan argumentasi yang dapat diterima. Sebagian masyarakat cukup memahami dengan argumentasi emosional, yaitu dengan memberikan kasus-kasus sosialkemasyaraakatan yang terjadi di lingkungannya. Sebagian lain dengan argumentasi konstitusional, yakni dengan menjelaskan aturan hukum dan hak-hak masyarakat. Tidak jarang juga harus dengan argumentasi dan penjelasan yang sifatnya doktrinal keagamaan. Karena itu temuan (Nafisah, 2018) relevan untuk dijadikan pijakan. Menurutnya, dari perspektif agama program Kampung $\mathrm{KB}$ ini penting karena perintah agama tentang kewajiban dalam pelestarian nyawa (diterapkan pada BKB dan BKL dengan pengasuhan yang baik dan penyiapan kehidupan lansia), pelestarian harta (diterapkan dalam UPPKS dengan memproduski makanan dan menanam sayuran untuk peningkatan ekonomi), serta pelestarian keturunan (diterapkan dalam BKR dengan memberi kasih sayang, pendidikan, sandang, pangan, dan papan serta perlindungan yang layak, serta memberi jarak kelahiran yang ideal). Lebih lanjut, dapat dikatakan, sesungguhnya penerapan Kampung KB sesuai dengan hukum Islam di mana kampung KB semata-mata untuk kebaikan dan kesejahtraan masyarakat (Aisyah, 2020) (Musyafaah, 2019).

Dari sini tergambar bahwa, implementasi Kampung KB sangat dipengaruhi oleh konten kebijakan dan konteks di mana kebijakan ini dilaksanakan. Selebihnya faktor pemahaman dan kesamaan bahasa dalam melihat Kampung KB mutlak diperlukan. Oleh sebab itu, dibutuhkan sosialisasi yang sistematis, sistemik, dan masif dengan menggunakan beragam media, argumetasi, dan strategi. Hal ini juga harus mengacu pada strategi difusiinovasi dan langkah-langkah yang dilakukan secara gradual.

Jumlah ribuan Kampung KB yang sudah dicanangkan terus mengalami pasang-surut menarik untuk dikaji. Keberhasilan penambahan Kampung KB secara kuantitas ini perlu dikuti dengan kegiatan-kegiatan yang berkualitas dengan mempertimbangkan aspek kontinuitas. Dengan demikian Kampung KB tidak berhenti pada kegiatan seremonial, tapi masuk ke dalam menjawab persoalan masyarakat yang substansial. Kampung KB sesuai dengan tujuannya mampu meningkatkan kualitas hidup keluarga dan masyarakat. Kampung KB secara pelan tapi pasti bergeser dari pembuatan gapura ke peningkatan kualitas hidup keluarga. 


\section{Implikasi Program Kampung KB bagi Kualitas Hidup Masyarakat}

World Health Organization (WHO) pada tahun 1947 memperkenalkan istilah kualitas hidup dalam konteks definisi tentang sehat, yaitu suatu kondisi fisik, mental, dan kesejahteraan sosial individu terbebas dari berbagai kelemahan dan penyakit. Konsep ini digunakan untuk mengukur atau menentukan kualitas hidup dari berbagai aspek. Para pakar berpendapat bahwa kualitas hidup adalah konsep yang berdimensi banyak. Kualitas hidup bersifat multidimensi, yang berarti tidak terbatas hanya dari fisik melainkan juga dari aspek psikologis (Fernandez, 1998).

Dengan kata lain, kualitas hidup merupakan konsep yang kompleks dengan berbagai aspek yang saling jalin-berkelindan di dalamnya. Aspek-aspek ini sering disebut sebagai dimensi. (Marinelli, R. D., \& Plummer, 2009) mengemukakan lima dimensi kualitas hidup meliputi dimensi fisik, emosional, sosial, intelektual, rohani, dan lingkungan. Sejalan dengan pendapat tersebut, (Kelley, 2009) menyebutkan, aspek yang paling berpengaruh terhadap kualitas hidup pada orang dewasa, yaitu: aspek fisik, emosional, sosial, intelektual, spiritual dan lingkungan.

Pertanyaanya, bagaimana implikasi program Kampung KB dalam peningkatan kualitas hidup keluarga? Sebuah eksplorasi yang menantang perlu dilakukan untuk mengidentikasi beberapa kegiatan di Kampung KB yang kemungkinan dapat menunjang dalam perwujudan kualitas hidup. (Novariani, 2020) secara khusus mengkaji Kegiatan Bina Keluarga Remaja dan pengaruhnya terhadap keharmonisan keluarga. Kajian ini dilatari oleh tiga hal: minimnya kepedulian orang tua terhadap perubahan pada diri remaja, kurangnya pengetahuan, dan keterampilan dalam membina hubungan harmonis dengan remaja, dan keterlambatan orang tua terhadap perilaku menyimpang yang dilakukan remaja. Berdasarkan hasil penghitungan statistik diketahui bahwa program bina keluarga remaja (X) berpengaruh positif terhadap keharmonisan keluarga (Y). Ini sejalan dengan temuan (Musfiroh, dkk 2019) tentang ketahanan keluarga di Kampung KB. Karena itu, disarankan agar PLKB dan Kader BKR lebih meningkatkan keterampilan dalam mengelola kegiatan, juga anggota BKR agar lebih aktif, kreatif, dan antusias dalam setiap kegiatan.

Aspek keharmonisan keluarga perlu mendapat perhatian, sebab menjadi salah satu bagian dari kualitas hidup keluarga, khususnya dari dimensi sosio-emosional. Keharmonisan keluarga mengalami tantangan yang semakin kompleks di tengah kehidupan digital yang serba cepat dan multi saluran. Masyarakat kini bukan hanya mengalami pemanasan global, tapi juga pendinginan global (Ferrucci, 2009). Indikasinya sederhana, yaitu hilangnya intimitas (kehangatan) di dalam keluarga. Hubungan antar anggota keluarga menjadi sangat mekanis dan kering. Tidak ada lagi kesempatan untuk saling berbagi cerita dan bercanda. Kesibukan masyarakat semakin memperburuk situasi ini. Semua seolah dituntut untuk sibuk, sebab tidak sibuk adalah aib yang harus dihindari. Sampai di sini, ajakan BKKBN pada masyarakat untuk kembali ke meja makan keluarga sungguh menemukan relevansinya.

Dimensi berikutnya dapat dilihat dari spiritual-intelektual masyarakat di Kampung KB. (Fitriana, 2020) melakukan kajian tentang pendidikan seks di salah satu Kampung KB. Ia memotret pendidikan seks bagi remaja dalam keluarga muslim di Kampung KB Kelurahan Kauman Kidul Kecamatan Sidorejo Kota Salatiga. Secara spesifik ia ingin mengetahui nilai- 
nilai pendidikan seks yang diberikan orang tua terhadap remaja, serta faktor pendukung dan penghambat dalam penerapan pendidikan seks bagi remaja. Hasil penelitiannya menunjukkan orang tua berusaha menanamkan nilai-nilai pada remaja agar patuh terhadap Allah, rasul, dan ulil amri, mendidik remaja agar bergaul secara sehat dan islami, berpakaian islami, menjaga kebersihan dan kesehatan badan, mengelola waktu, serta mengingatkan remaja agar berhatihati dalam bertindak. Orang tua di Kampung KB memiliki pemahaman yang baik mengenai bahaya pergaulan bebas, sumber pendidikan seks yang beragam dan mudah diakses, adanya aturan, hukuman/sanksi, dan karakter remaja. Tantangan dan hambatan yang dihadapi orang tua dalam pendidikan seks adalah pergaulan remaja yang semakin permisif dan penggunaan telepon seluler yang semakin masif.

Dalam dimensi fisik, perlindungan, rasa aman, dan terbebas dari intimidasi, diskriminasi, dan kekerasan juga menjadi bagian dari kualitas hidup masyarakat. (Ifroh, dkk 2019) memfokuskan kajiannya pada perilaku bullying siswa sekolah dasar di Kampung KB Pelita Kencana. Dalam studi pendahuluan ditemukan kejadian bullying dan kasus pelecehan seksual di wilayah kampung KB Pelita Kencana. Bullying dilakukan oleh anak sekolah dengan teman sebayanya, mereka saling mengolok nama orang tua dan pekerjaan orang tua. Pelecehan seksual juga terjadi pada seorang siswi. Karena itu peneliti menindaklanjuti studinya dengan pengabdian masyarakat berupa pelibatan ketua kampung KB serta kader KB untuk mengadakan pendidikan kesehatan bagi anak sekolah. Pendidikan kesehatan penting dilakukan untuk mengurangi angka kasus bullying dan pelecehan seksual yang terjadi di Kampung KB.

Sejalan dengan ini, di Kampung KB juga dilakukan kegiatan deteksi dini kanker leher rahim (Purba, dkk 2019). Kegiatan pendidikan kesehatan tentang deteksi dini kanker servik berisi penyampaian materi tentang: manfaat, jadwal pemeriksaan, tanda dan gejala mengalami masalah pada genitalia serta pencegahan kanker servik. Materi ini juga dibuat dalam leaflet yang dibagikan kepada ibu. Pemberian penyuluhan ternyata efektif meningkatkan motivasi ibu-ibu di Kampung KB untuk memelihara dan meningkatkan kesehatannya. (Septianingrum, 2019) melakukan kajian serupa tentang tanaman obat tradisional di Kampung KB.

Dimensi sosial dan lingkungan sedikit terkanalisasi lewat kegiatan gotong royong dalam pemilahan dan pengelolaan sampah di Kampung KB. Ini sekaligus menjadi potret keluarga mandiri, yakni keluarga yang berupaya meningkatkan kepedulian masyarakat, mendewasakan usia perkawinan, membinan dan meningkatkan ketahanan keluarga, mengatur kelahiran dan mengembangkan kualitas dan kesejahteraan keluarga, berdasarkan kesadaran dan tanggung jawab. Secara emosional mereka antusias dan bangga terlibat aktif dalam kegiatan Kampung KB. Secara sosial berhubungan baik denga para kader, bidan dan warga, serta bertukar pikiran tentang pola asuh anak. Dari sisi kemandirian ekonomi, meskipun belum sepenuhnya, masyarakat mampu mengatur, memenuhi, mengatasi masalah ekonomi sendiri melalui Usaha Peningkatan Pendapatan Keluarga Sejahtera (UPPKS) yang merupakan alternatif kegiatan ekonomi produktif untuk meningkatkan pendapatan keluarga (Nani, dkk 2019), (Novatna, Sarah dan Adnan, 2020)

Demikian beberapa kegiatan di Kampung KB yang sudah mengarah pada peningkatan kualitas hidup keluarga dan masyarakat. Meskipun belum ada yang melakukan 
pengukuran seberapa jauh mampu mengakselarasi kualitas hidup keluarga dan masyarakat, namun kegiatan-kegiatan ini jika dilakukan secara kontinyu akan bermuara pada peningkatan kualitas hidup.

Ke depan perlu diperbanyak kegiatan-kegiatan serupa dengan pendekatan yang lebih beragam dan melibatkan banyak pihak (Sulastri, dkk 2020), (Syahnur, dkk 2019). Keberhasilan implementasi Kampung KB akan berimplikasi pada kualitas hidup keluarga dan masyarakat setempat. Peningkatan kualitas hidup warga Kampung KB, akan berimbas pada peningkatan kualitas masyarakat yang lebih luas. Pada gilirannya, akan meningkatkan kualitas hidup masyarakat Indonesia dari Sabang hingga Marauke.

Karena itu, implementasi Kampung KB ke depan perlu memperhatikan beberapa hal. Pertama, perlu penguatan tentang pengelolaan Kampung KB. Kedua, Optimalisasi kegiatan yang berdampak pada peningkatan program KKBPK dan peningkatan kualitas keluarga dan masyarakat. Ketiga, perlu monitoring dan evaluasi secara berkala dan terpadu (BKKBN, 2019). Lebih dari itu, sebagaimana temuan banyak penelitian sebelumnya, kunci keberhasilan implementasi Kampung KB ke dapan tidak akan lepas dari: komitmen yang tinggi pemerintah daerah, pemanfaatan data masalah dan potensi desa, partisipasi masyarakat, serta integrasi lintas komponen.

\section{KESIMPULAN}

Berdasar analisis dari berbagai artikel dalam kajian ini dapat disimpulkan dua hal. Pertama, Kampung KB dari sisi kuantitas semakin bertambah jumlahnya tiap tahun. Dengan segala keterbatasan yang ada, Kampung KB dapat diimpelementasikan di banyak lokasi. Tantangan dan hambataan tiap daerah berbeda. Untuk mencapai keberhasilan dalam implementasi Kampung KB diperlukan pemahaman yang utuh dan menyeluruh dari masyarakat dan pengelola. Karena itu, selain perlu dilihat konten dan konteks Kampung KB sebagai sebuah kebijakan, perlu juga diperhatikan tahapan dalam sosialisasi, serta koordinasi lintas sektor di lapangan. Kedua, sudah banyak kegiatan di Kampung KB yang mengarah pada peningkatan kualitas hidup keluarga dan masyarakat. Hasil beberapa kajian menunjukkan adanya kegiatan yang mengarah pada pemenuhan dimensi kualitas hidup, yakni: fisik, emosional, sosial, intelektual, spiritual, dan lingkungan.

\section{DAFTAR RUJUKAN}

Aisyah, S. dan S. (2020). Analisis Hukum Islam Terhadap Penerapan Kampung Keluarga Berencana (Kb) (Studi Kasus Di Desa Inrello Kecamatan Keera Kabupaten Wajo). Jurnal Perbandingan Mą̧ab, 2(1).

Aji, Maulana Satria, \& Yudianto, G. P. H. (2020). Pemberdayaan Masyarakat "Kampung KB" Ditinjau dari Perspektif Ottawa Charter. Jurnal PROMKES, 8(2), 206.

Arinta, F. (2018). Efektivitas Program Kampung KB Guna Mewujudkan Keluarga Kecil Mandiri (Studi Kasus: Tiga Orang Penerima Program Kampung KB di Lingkungan IX Kelurahan Harjosari II). Repositori Institusi USU, Univsersitas Sumatera Utara.

Bachtiyar, Nosa Arighi, \& Wibawani, S. (2018). Implementasi Program Kampung Keluarga 
Berencana Di Dusun Ambeng-Ambeng Desa Ngingas Kecamatan Waru Kabupaten Sidoarjo. Jurnal Ilmu Administrasi Negara, 7(1), 2656-9949.

BKKBN. (2015). Keluarga Berencana dan Kontrasepsi. Jakarta: Pustaka Sinar Harapan.

BKKBN. (2018). Panduan Kampung KB Percontohan. Jakarta: Direktorat Bina Lini Lapangan.

BKKBN. (2019). Kampung KB Sebagai Upaya Bersama Untuk Indonesia Sejabtera. Jakarta: Direktorat Bina Lini Lapangan.

Fernandez, B. (1998). Quality of Life: Concept and assessment”, Advances in Psychological science Book. Oxford: Psychology Press.

Ferrucci, P. (2009). Bagaimana Menjadi Orang Baik. Jakarta: Libri.

Fitriana. (2020). Pendidikan Seks Bagi Remaja Dalam Keluarga Muslim di Kampung Keluarga Berencana (KB) Kelurahan Kauman Kidul Kecamtan Sidorejo Kota Salatiga. IAIN Salatiga.

Hakim, C. (1987). Research Design: Strategies and Choices in The Design of Social Research. London: Routledge.

Handayani, Arri, Najib, Ardini, Sukma Nur, \& Yulianti, P. D. (2020). The Evaluation Studies Of Kampung KB In Central Java. JKKP (Jurnal Kesejabteraan Keluarga Dan Pendidikan), 7(1), 63-73.

Hidayah, Seventina Nurul, \& Latifah, U. (2018). mplementasi Program Kampung Kb Sebagai Inovasi Strategis Pencegahan 4t (4 Terlalu) Dalam Kehamilan Di Rw 10 Margadana, TEGAL. JURNAL KEBIDANAN, 8(2), 130.

HM, Rahman, \& Indrawadi, J. (2019). Implementasi Program Kampung KB dalam

Meningkatkan Kesejahteraan Masyarakat di Kelurahan Gunung Pangilun Kecamatan

Padang Utara Kota Padang. Journal of Civic Education, 2(4), 295-301.

Ifroh. (2019). Pemberdayaan Siswa Sekolah Dasar Di Wilayah Kampung Kb Pelita Kencana

Kelurahan Pelita Mengenai Bullying Usia Sekolah. Jurnal Pengabdian Kepada Masyarakat, 1(3), 183.

Kelley, G. (2009). An Integrated Conceptual Model of Quality of Life for Older Adults Based on a Synthesis of the Literature. Journal Applied Research Quality Life, 4, 269.

Lathifatun Nafisah. (2018). EFEKTIVITAS PROGRAM KAMPUNG KB (KELUARGA BERENCANA) DALAM MEMBENTUK KELUARGA SEJAHTERA DI KOTA YOGYAKARTA. Institutional Repository UIN Sunan Kalijaga.

Marinelli, R. D., \& Plummer, O. K. (2009). Healthy Aging: Beyond Exercise. Journal Activities, Adaptation \& Aging, 23(4), 1-11.

Muliawaty, L. dan M. (2019). Strategi Implementasi Kebijakan Tentang Program Kampung Keluarga Berencana Menuju Keluarga Sejahtera Di Kabupaten Cirebon. Decision: Jurnal Administrasi Publik, 1(2), 82.

Musfiroh, Mujahidatul, Mulyani, Sri, Cahyanto, Erindra Budi, Nugraheni, Angesti, \& Sumiyarsi, I. (2019). Analisis Faktor-Faktor Ketahanan Keluarga Di Kampung Kb Rw 18 Kelurahan Kadipiro Kota Surakarta. PLACENTUM: Jurnal Ilmiah Kesehatan Dan Aplikasinya, 7(2), 61.

Musyafaah, N. L. (2019). Analisis Program Kampung Keluarga Berencana Perspektif Maqā̦id Al-Syarỉah (Studi di Kampung Logam Ngingas Waru Sidoarjo Jawa Timur). Al-Manabij: Jurnal Kajian Hukum Islam, 13(2), 259-279.

Nani. (2019). Kajian Peningkatan Pendapatan Keluarga (Studi Pada Program UPPKS Kampung KB). JURNAL ECONOMIC RESOURCE, 2(1), 76-86.

Nasir, M. (1985). Metode Penelitian. Jakarta: Ghalia Indonesia.

Normajatun, Normajatun, Malawat, Sitna Hajar, \& Fibriyanita, F. (2019). Implementasi Kebijakan Program Kampung Keluarga Berencana-Kampung Baiman (Kkb-Kb) Di Kota Banjarmasin. Jurnal Ilmu Sosial Dan Ilmu Politik, 3(2), 47. 
Novariani, P. (2020). Pengaruh Program Bina Keluarga Remaja (BKR) terhadap Keharmonisan Keluarga di Kampung KB Berkah Bersama Kelurahan Air Dingin Kecamatan Bukit Raya Kota Pekanbaru. Skirpsi UIN Sultan Syarif Kasim. UIN Sultan Syarif Kasim.

Novatna, Sarah dan Adnan, M. (2020). Efektivitas Pemberdayaan Masyarakat Kampung Keluarga Berencana di Kota Padang. Journal of Civic Education, 3(1).

Nugroho Muhammad. (2018). Sosialisasi Program Kampung Keluarga Berencana (kampung kb) Di Kelurahan Pucang Sawit. Skripsi Thesis, Universitas Mubammadiyah Surakarta.

Nurjannah, Siti Nunung, \& Susanti, E. (2018). Implementasi Program Kampung Keluarga Berencana $(\mathrm{Kb})$ di Kabupaten Kuningan Tahun 2018 (Studi Kuantitatif Dan Kualitatif). Jurnal Ilmu Kesehatan Bhakti Husada: Health Sciences Journal, 9(2), 27-33.

Purba, Agnes, Simanjuntak, Eva Hotmaria, \& Saragih, F. L. (2019). (2019). Deteksi Dini Kanker Leher Rahim di Kampung KB Desa Percut Sei Tuan. Jurnal Pengabdian Masyarakat, 1(1), 64.

Restiyani, Ni Luh Novi dan Yasa, I. G. W. M. (2019). Efektivitas Program Kampung Keluarga Berencana (Kb) Dan Dampaknya Terhadap Kesejahteraan Keluarga Miskin Di Kota Denpasar. E-Jurnal Ekonomi Dan Bisnis, 711.

Septianingrum. (2019). Pemanfaatan dan Penggunaan Secara Rasional Tanaman Obat Tradisional Sebagai Terapi Swamedikasi di Kampung KB, Magersari Kota Magelang. Jurnal Pengabdian Kepada Masyarakat, 3(2).

Sulastri, Sri, Krisnani, Hetty, \& Hidayat, E. N. (2020). Pengembangan Kapasitas Pengurus Kampung Kb Dalam Pencatatan Dan Pengolahan Data Mikro Keluarga. Jurnal Pengabdian Kepada Masyarakat, 3(2), 174.

Syahnur, Sofyan, Diantimala, Yossi, \& Ilham, R. (2019). Identifikasi Kegiatan Program Kampung Keluarga Berencana di Kabupaten Aceh Tengah. JPPUMA Jurnal Ilmu Pemerintahan Dan Sosial Politik Universitas Medan Area, 7(1), 71.

Zed, M. (2014). Metode Penelitian Kepustakaan. Jakarta: Yayasan Obor Indonesia. 